\title{
Tissue transglutaminase-2 promotes gastric cancer progression via the ERK1/2 pathway
}

\author{
Xiaofeng Wang ${ }^{1, *}$, Zhenjia Yu ${ }^{1, *}$, Quan Zhou ${ }^{1}$, Xiongyan Wu ${ }^{1}$, Xuehua Chen ${ }^{1}$, \\ Jianfang $\mathrm{Li}^{1}$, Zhenggang Zhu ${ }^{1}$, Bingya Liu ${ }^{1}$ and Liping Su${ }^{1}$ \\ 1 Shanghai Key Laboratory of Gastric Neoplasms, Shanghai Institute of Digestive Surgery, Department of Surgery, Ruijin \\ Hospital, Shanghai Jiao Tong University School of Medicine, Shanghai, People's Republic of China \\ * These authors have contributed equally to this work
}

Correspondence to: Liping Su, email: franesulp@hotmail.com

Keywords: TG2, gastric cancer, ERK1/2, tumor progression

Received: August 26, $2015 \quad$ Accepted: January 04, $2016 \quad$ Published: January 11, 2016

\section{ABSTRACT}

Gastric cancer (GC) is one of the most common tumors worldwide and involves extensive local tumor invasion, metastasis, and poor prognosis. Understanding mechanisms regulating progression of GC is necessary for developing effective therapeutic strategies. Tissue transglutaminase-2 (TG2), a multifunctional member of the transglutaminase family, has been shown to be critical for tumor initiation and progression. However, how TG2 promotes the progression of GC is unknown. We report that TG2 was highly expressed in GC tissues and positively associated with depth of tumor invasion and late TNM stage. With gain- and loss-of-function approaches, we observed that TG2 promoted GC cell proliferation, migration, invasion, as well as tumorigenesis and peritoneal metastasis in vivo. These events were associated with the ERK1/2 pathway activation and an ERK1/2 inhibitor (U0126) inhibited cell proliferation, migration, and invasion induced by overexpression of TG2. In summary, TG2 contributes to tumorigenesis and progression of GC by activating the ERK1/2 signaling pathway and is a potential therapeutic target of metastatic gastric cancer.

\section{INTRODUCTION}

Gastric cancer (GC) is one of the most frequent tumors worldwide and the third leading cause of tumor death according to GLOBOCAN 2012 [1]. Although appropriate surgical resection and adjuvant treatments such as radiotherapy and chemotherapy are used to treat GC, 5-year survival is less than $20 \%$ [2] due to local tumor invasion, systemic dissemination, metastases, and recurrence. Therefore, a better understanding of molecular mechanisms accounting for GC development and progression could contribute to prevention, diagnosis, and treatment of GC.

Tissue transglutaminase-2 (TG2 or tTG), the most complex member of the transglutaminase (TGase) family, is a calcium-dependent cross-linking enzyme that catalyzes protein modifications via transamidation to facilitate formation of lysine combinations or polyaminated proteins in the presence of calcium [3, 4]. TG2 is expressed ubiquitously and abundantly in various subcellular areas including the cytosol, nucleus, cellular membrane, and the extracellular matrix (ECM) [5-7]. TG2 is a multifunctional molecule that can bind to GTP and has hydrolysis [8], protein disulfide isomerase [9], and protein kinase activity independent of calcium [10]. Furthermore, TG2 has calcium-independent non-enzymatic activity, interacting with many cell surface proteins [11], participating in inflammation, differentiation, apoptosis, cell migration, wound healing, neurodegenerative disorder, and cancer [12-15].

Recently, accumulated evidence indicates that TG2 is involved in tumor formation and progression by organizing the ECM, regulating cancer cell adhesion to the endothelium, as well as controlling migration and invasion of cancer cells and angiogenesis of tumor tissue [16]. Elevated TG2 expression has been observed in breast [17], pancreatic [18], colon [19], lung [20] and ovarian cancers [21], and it has been correlated with cell survival and high tumor invasiveness. For example, in non-small cell lung cancer, progression-free survival (PFS) of high-expressing TG2 patients was shorter than that of low-expressing TG2 patients [20]. In addition, TG2 promoted ovarian tumor 
Table 1: Association between TG2 expression and clinicopathological parameters in 127 pairs of GC tissues

\begin{tabular}{|c|c|c|c|c|c|}
\hline \multirow{2}{*}{ Variables } & \multirow{2}{*}{$\begin{array}{c}\begin{array}{c}\text { Number } \\
\text { cases }\end{array} \\
\end{array}$} & \multicolumn{3}{|c|}{ TG2 immunostaining } & \multirow{2}{*}{$P$ value } \\
\hline & & $++(n=67)$ & $+(n=38)$ & $\pm 0 r-(n=22)$ & \\
\hline \multicolumn{6}{|l|}{ Gender } \\
\hline male & 86 & 49 & 24 & 13 & \multirow{2}{*}{0.365} \\
\hline female & 41 & 18 & 14 & 9 & \\
\hline \multicolumn{6}{|l|}{ Age(years) } \\
\hline$<60$ & 59 & 32 & 21 & 6 & \multirow{2}{*}{0.106} \\
\hline$>60$ & 68 & 35 & 17 & 16 & \\
\hline \multicolumn{6}{|l|}{ Tumor size $(\mathrm{cm})$} \\
\hline$<5$ & 37 & 19 & 12 & 6 & \multirow{2}{*}{0.92} \\
\hline$>5$ & 90 & 48 & 26 & 16 & \\
\hline \multicolumn{6}{|l|}{ Differentiation } \\
\hline Poorly, undifferentiated & 98 & 54 & 30 & 14 & \multirow{2}{*}{0.246} \\
\hline Well, moderately & 29 & 13 & 8 & 8 & \\
\hline \multicolumn{6}{|l|}{ T stage } \\
\hline $\mathrm{T} 1+\mathrm{T} 2$ & 29 & 9 & 12 & 8 & \multirow{2}{*}{$0.026^{*}$} \\
\hline $\mathrm{T} 3+\mathrm{T} 4$ & 98 & 58 & 26 & 14 & \\
\hline \multicolumn{6}{|l|}{ Lymphnode metastasis } \\
\hline Negative & 37 & 14 & 13 & 10 & \multirow{2}{*}{0.063} \\
\hline Positive & 90 & 53 & 25 & 12 & \\
\hline \multicolumn{6}{|l|}{ Distant metastasis } \\
\hline Negative & 97 & 55 & 27 & 15 & \multirow{2}{*}{0.269} \\
\hline Positive & 30 & 12 & 11 & 7 & \\
\hline \multicolumn{6}{|l|}{ TNM stage } \\
\hline $\mathrm{I}+\mathrm{II}$ & 46 & 17 & 16 & 13 & \multirow{2}{*}{$0.011 *$} \\
\hline III+IV & 81 & 50 & 22 & 9 & \\
\hline \multicolumn{6}{|l|}{ Lauren classification } \\
\hline Intestinal & 55 & 31 & 16 & 8 & \multirow{2}{*}{0.707} \\
\hline Diffuse & 72 & 36 & 22 & 14 & \\
\hline
\end{tabular}

metastasis by inducing a cancer stem cell phenotype and epithelial-to-mesenchymal transition (EMT) [22]. Even so, a precise role for TG2 in the development and progression of GC has not been well defined.

Here we measured TG2 expression in GC tissues and corresponding non-tumor mucosal tissues and explored the role and underlying mechanism of TG2 with respect to $\mathrm{GC}$ progression using in vitro and in vivo models. TG2 expression was frequently elevated in GC and associated with tumor depth of invasion and late TNM stage. In addition, TG2 promoted GC cell proliferation, migration, and invasion in vitro, as well as tumorigenesis and peritoneal metastasis in vivo through activation of the ERK1/2 pathway in GC cells. Thus, TG2 is a potential therapeutic target for treatment of metastatic GC.

\section{RESULTS}

\section{TG2 expression is upregulated in GC cells and associated with clinicopathology}

To elucidate the role of TG2 in human GC, we measured TG2 expression in human GC cell lines and GC tissues. TG2 mRNA in six GC cell lines, one normal gastric epithelial cell line (GES-1), and 50 pairs of human GC and matched adjacent non-tumor tissues was measured with qRT-PCR. As shown in Figure 1A, TG2 mRNA expression was significantly up-regulated in GC cell lines compared with normal GES-1 cells. Moreover, TG2 mRNA in GC tissues was higher than in non-tumor tissues (Figure 1C and 1D) and this finding was confirmed with Western blot (Figure 1B).

Upregulated TG2 expression was assayed in $127 \mathrm{GC}$ and matched non-tumor tissue pairs using immunohistochemistry (IHC) as depicted in Methods. Of all GC tissues, $82.7 \%$ were positive for TG2 protein 
expression and 22 GC tissues and 88 adjacent normal tissues were negative for TG2 protein or had weak expression (Figure 1E; $P<0.05$ ). Typical immunostaining of TG2 in normal and GC tissues was shown in Figure $1 \mathrm{~F}$ and positive TG2 protein staining occurred in the cytoplasm of GC cells. Elevated TG2 protein expression in tumor tissues was significantly associated with depth of tumor invasion $(P=0.026)$ and late TNM stage $(P$ $=0.011$ ), but not with other parameters (see Table 1). Thus, TG2 expression is up-regulated in GC cells and is associated with tumor severity.

B

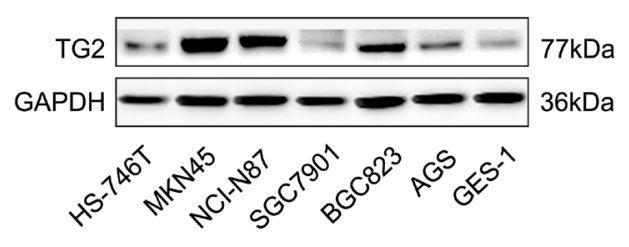

$\mathbf{E}$

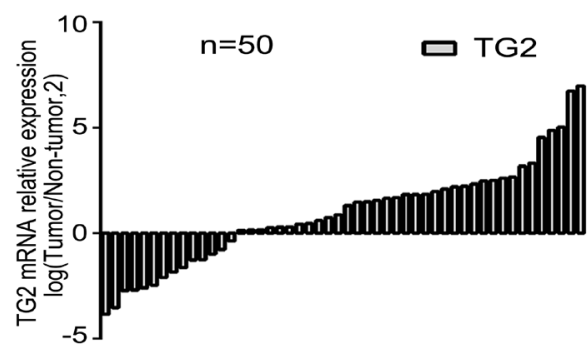

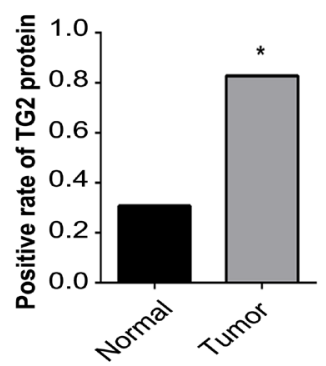

$\mathbf{F}$
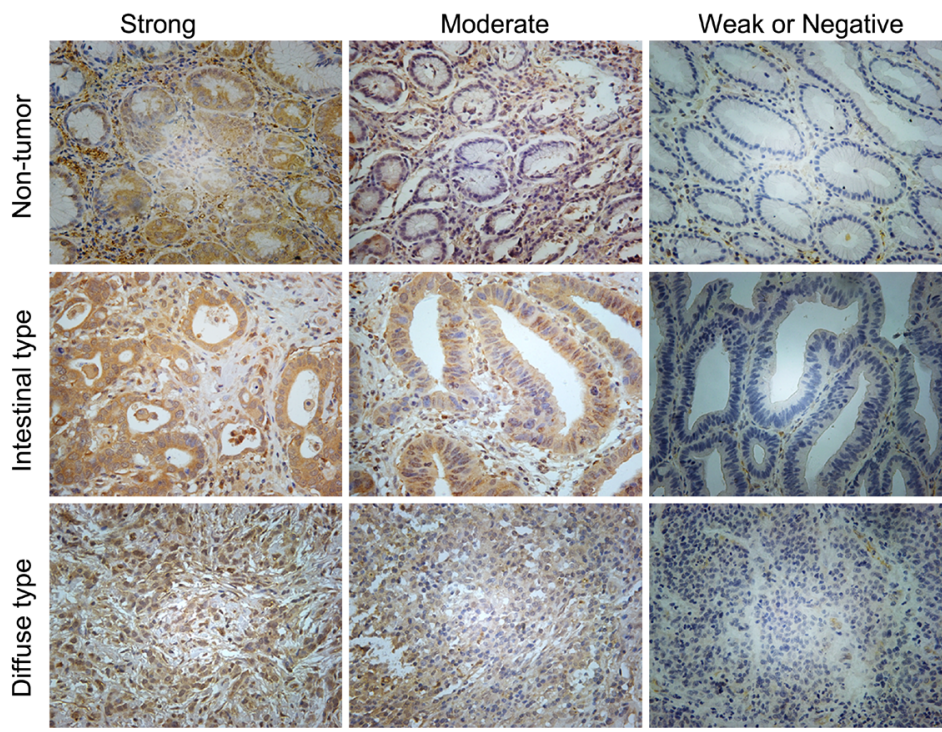

Figure 1: Expression of TG2 in the GC tissues and cell lines. A. TG2 mRNA expression in GC cell lines and a normal gastric epithelial cell line GES-1 was analyzed by qRT-PCR. B. TG2 protein expression in human GC cell lines and a normal gastric epithelial cell line GES-1 was examined by Western blot. C. and D. TG2 mRNA expression in 50 gastric cancer tissues and adjacent non-tumor tissues was analyzed by qRT-PCR. Data are $2^{-\Delta C t}\left({ }^{*} P<0.05\right)$. E. Positive ratios of TG2 protein expression in 127 pairs of gastric cancer tissues. F. Expression of TG2 was examined with immunohistochemistry (IHC) in non-tumor gastric tissues, intestinal-type GC tissues, and diffusetype GC tissues, and classified as strong expression $(++)$, moderate expression $(+)$, weak positive or negative expression $( \pm$ or -$)$. Original magnification: 200x. 


\section{TG2 promotes GC cell proliferation}

Given that TG2 is frequently overexpressed in GC, it may act as an oncogene. To study this, we measured cell growth in cells that variously expressed TG2. TG2 was highly expressed in GC cell lines compared with a normal gastric epithelial cell line GES-1. We also silenced TG2 in MKN45 and NCI-N87 cells using small interfering RNA. TG2-shRNA was transfected into MKN45 and NCI-N87 cells to knock down TG2 expression and Figure 2A showed that TG2 decreased in TG2-shRNA-transfected cells. With TG2 expression modification confirmed, we measured cell proliferation and noted that proliferation in both MKN45/TG2-shRNA and NCI-N87/TG2shRNA cells was slower than in negative controls and mock groups (Figure 2C and 2D). Additionally, a TG2expressing plasmid vector was transfected into SGC7901 and AGS cells, which expressed less TG2 (Figure 2B). We noted that SGC7901/TG2 and AGS/TG2 cells grew faster than vector and mock groups (Figure $2 \mathrm{E}$ and $2 \mathrm{~F}$ ). Thus, TG2 promotes GC cell proliferation.

\section{TG2 enhances migration and invasion of GC cells}

We assessed TG2 on GC cell migration and invasion, which are key determinants of malignant
A

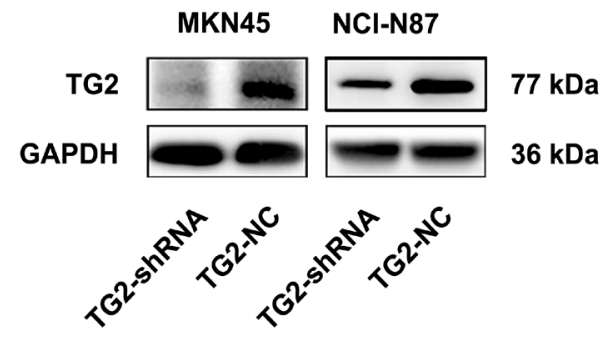

C

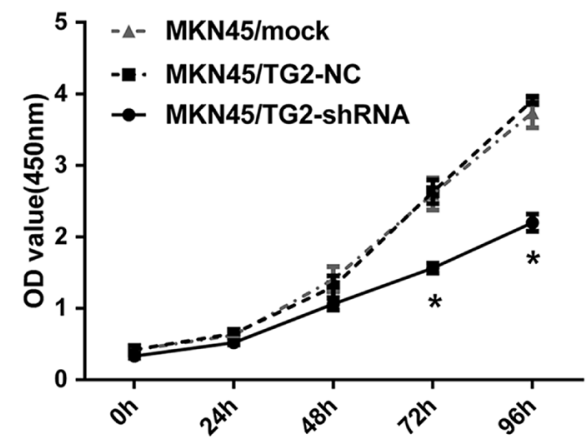

E

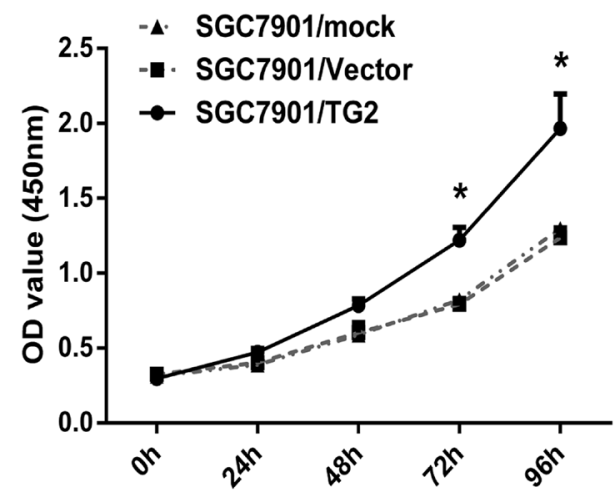

B

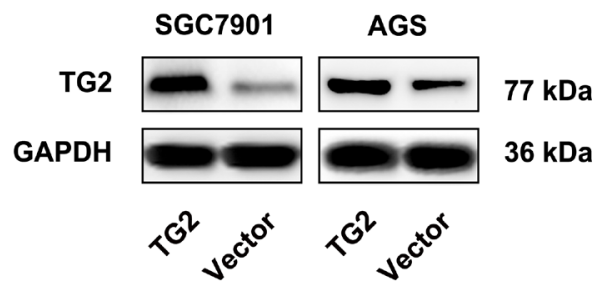

D

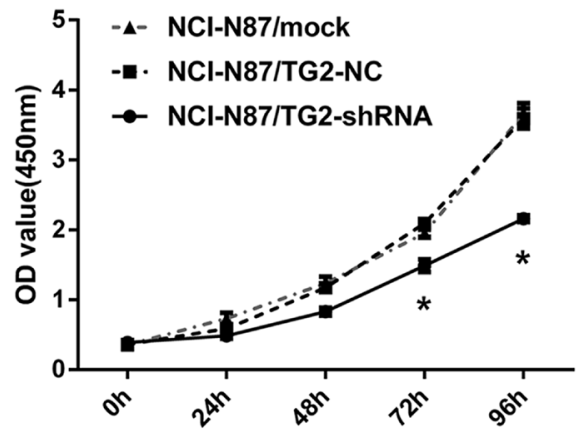

$\mathbf{F}$

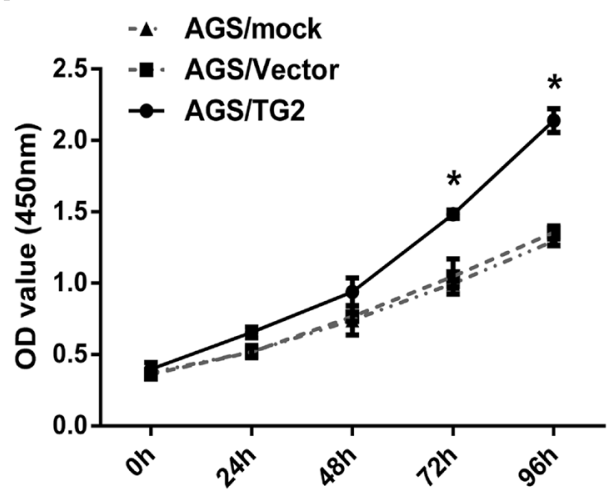

Figure 2: TG2 promotes GC cell proliferation. A. TG2 protein expression in MKN45 and NCI-N87 cells transfected with TG2shRNA was quantified with Western blot. B. TG2 protein expression in SGC7901 and AGS cells transfected with TG2-constructed plasmid. C. and D. The effect of TG2 knockdown on MKN45 and NCI-N87 cell proliferation was measured by CCK8 assay. E. and $\mathbf{F}$. The effect of TG2 overexpression on SGC7901 and AGS cell proliferation was measured by CCK8 assay. Data are means \pm SD of three independent experiments $(* P<0.05)$. 
progression and metastasis, using Transwell assays. As shown in Figure $3 \mathrm{~A}$ and $3 \mathrm{~B}$, knockdown of TG2 decreased migration (MKN45/TG2-shRNA: 65.60 \pm 5.37 cells per field; MKN45/TG2-NC: $170.20 \pm 7.40$ cells per field; MKN45/mock: 167.20 \pm 6.78 cells per field; MKN45/ TG2-shRNA vs. MKN45/TG2-NC or MKN45/mock: $P<$ 0.05 ) and invasion (MKN45/TG2-shRNA: $36.20 \pm 3.48$ cells per field; MKN45/TG2-NC: $68.20 \pm 4.52$ cells per field; MKN45/mock: 71.80 \pm 1.16 cells per field; MKN45/ TG2-shRNA vs. MKN45/TG2-NC or MKN45/mock: $P<0.05)$ of MKN45 cells. Similarly, in NCI-N87 cells, knockdown of TG2 decreased migration (NCI-N87/TG2shRNA: $52.00 \pm 2.67$ cells per field; NCI-N87/TG2-NC: $163.00 \pm 5.04$ cells per field; NCI-N87/mock: $170.00 \pm 1.64$ cells per field; NCI-N87/TG2-shRNA vs. NCI-N87/TG2NC or NCI-N87/mock: $P<0.05)$ and invasion (NCI-N87/ TG2-shRNA: $42.20 \pm 5.09$ cells per field; NCI-N87/ TG2-NC: $131.60 \pm 7.00$ cells per field; NCI-N87/mock: $139.40 \pm 4.19$ cells per field; NCI-N87/TG2-shRNA vs. NCI-N87/TG2-NC or NCI-N87/mock: $P<0.05$ ) (Figure $3 \mathrm{C}$ and $3 \mathrm{D})$. Consistent with these observations, the number of cells migrating through the Transwell chamber in the TG2-overexpressed group was significantly higher than in the vector and mock groups for both SGC7901 and AGS cells (SGC7901/TG2: $239.00 \pm 11.00$ cells per field; SGC7901/Vector: $124.00 \pm 15.52$ cells per field; SGC7901/ mock: $133.33 \pm 21.03$ cells per field; SGC7901/TG2 vs. SGC7901/Vector or SGC7901/mock: $P<0.05$; AGS/TG2: 133.00 \pm 7.94 cells per field; AGS/Vector: $65.33 \pm 10.12$ cells per field; AGS/mock: $70.00 \pm 11.79$ cells per field; AGS/ TG2 vs. AGS/Vector or AGS/mock: $P<0.05)$. Similar data were obtained in invasion assays with SGC7901 and AGS cells (SGC7901/TG2: 160.00 \pm 11.53 cells per field; SGC7901/Vector: $76.33 \pm 11.37$ cells per field; SGC7901/ mock: 75.00 \pm 5.57 cells per field; SGC7901/TG2 vs. SGC7901/Vector or SGC7901/mock: $P<0.05$; AGS/TG2: $105.33 \pm 5.69$ cells per field; AGS/Vector: $60.07 \pm 8.02$ cells per field; AGS/mock: $64.67 \pm 12.66$ cells per field; AGS/ TG2 vs. AGS/Vector or AGS/mock: $P<0.05$ ) (Figure $3 \mathrm{E}, 3 \mathrm{~F}, 3 \mathrm{G}$, and $3 \mathrm{H})$. Thus, TG2 enhances migration and invasion of GC cells.

\section{TG2 regulates cell proliferation, migration, and invasion via activation of the ERK1/2 pathway}

The ERK1/2 signaling pathway has been reported to be involved in cell growth [16] and migration [23]. Thus, we measured TG2 and assessed whether it could modulate activation of the ERK1/2 signaling pathway in GC cells. Figure $4 \mathrm{~A}$ and $4 \mathrm{~B}$ showed that ERK1/2 phosphorylation in MKN45 and NCI-N87 cells, which overexpressed TG2, was greater than in SGC7901 and AGS cells, which expressed less TG2. In contrast, TG2 knockdown significantly inhibited phosphorylation of ERK1/2 in MKN45/TG2-shRNA and NCI-N87/TG2shRNA cells (Figure 4C and 4D) and TG2 overexpression promoted phosphorylation of ERK1/2 in SGC7901/TG2 and AGS/TG2 cells (Figure 4E and 4F). Therefore, TG2 may be involved in the ERK1/2 pathway regulation as an upstream molecule. We next investigated whether TG2 could regulate cell proliferation, migration, and invasion via the ERK1/2 pathway by treating SGC7901/TG2 and AGS/TG2 cells with an ERK1/2 inhibitor (U0126) (20 $\mu \mathrm{M})$. Western blot and cell proliferation assays indicated that (Figure 4G) ERK1/2 was inhibited, TG2 expression did not change, and SGC7901/TG2 and AGS/TG2 cells growth decreased after treatment with U0126 compared with control or mock cells (Figure 4H and 4I). In addition, after treatment with U0126, migration (SGC7901/ TG2-U0126: 75.00 \pm 7.00 cells per field; SGC7901/ TG2-DMSO: $169.00 \pm 16.64$ cells per field; SGC7901/ TG2-mock: 167.00 \pm 15.62 cells per field; SGC7901/ TG2-U0126 vs. SGC7901/TG2-DMSO or SGC7901/ TG2-mock: $P<0.05$ ) and invasiveness (SGC7901/ TG2-U0126: 60.33 111.06 cells per field; SGC7901/TG2DMSO: $140.67 \pm 10.07$ cells per field; SGC7901/TG2mock: $155.33 \pm 16.80$ cells per field; SGC7901/TG2-U0126 vs. SGC7901/TG2-DMSO or SGC7901/TG2-mock: $P<$ $0.05)$ of SGC7901/TG2 cells were significantly decreased (Figure 4J and 4K) and AGS/TG2 cells migrated (AGS/ TG2-U0126: 75.33 \pm 7.23 cells per field; AGS/TG2DMSO: $162.33 \pm 13.05$ cells per field; AGS/TG2-mock: $163.33 \pm 17.56$ cells per field; AGS/TG2-U0126 vs. AGS/ TG2-DMSO or AGS/TG2-mock: $P<0.05)$ less and were less invasive (AGS/TG2-U0126: $55.00 \pm 7.81$ cells per field; AGS/TG2-DMSO: $146.67 \pm 8.62$ cells per field; AGS/TG2-mock: 138.33 \pm 8.02 cells per field; AGS/ TG2-U0126 vs. AGS/TG2-DMSO or AGS/TG2-mock: $P$ $<0.05$ ) (Figure $4 \mathrm{~L}$ and $4 \mathrm{M}$ ). Therefore, TG2 regulates cell proliferation, migration, and invasion via activation of the ERK1/2 pathway, which contributes to the development and progression of human GC.

\section{TG2 facilitates tumor growth, peritoneal spread, and metastasis in vivo}

Next, we assessed whether knockdown of TG2 repressed tumor growth and metastasis in vivo. Figure $5 \mathrm{~A}, 5 \mathrm{~B}$, and $5 \mathrm{C}$ showed that tumor growth from MKN45/ TG2-shRNA cells and NCI-N87/TG2-shRNA cells was slower than in negative controls. Moreover, average tumor weights from MKN45/TG2-shRNA and NCI-N87/ TG2-shRNA cells were significantly lower than weights of tumors from MKN45/TG2-NC and NCI-N87/TG2NC cells (MKN45/TG2-shRNA: $0.20 \pm 0.06 \mathrm{~g}$; MKN45/ TG2-NC: $0.46 \pm 0.12 \mathrm{~g}$; MKN45/TG2-shRNA vs. MKN45/ TG2-NC: $P<0.05$; NCI-N87/TG2-shRNA: $0.52 \pm 0.10 \mathrm{~g}$; NCI-N87/TG2-NC: $1.07 \pm 0.13 \mathrm{~g}$; NCI-N87/TG2-shRNA vs. NCI-N87/TG2-NC: $P<0.05$ ) (Figure 5D). Ki-67 antigen expression measured using IHC indicated (Figure 5E) fewer Ki-67 antigen-positive cells in tumors derived from MKN45/TG2-shRNA or NCI-N87/TG2-shRNA cells 
A

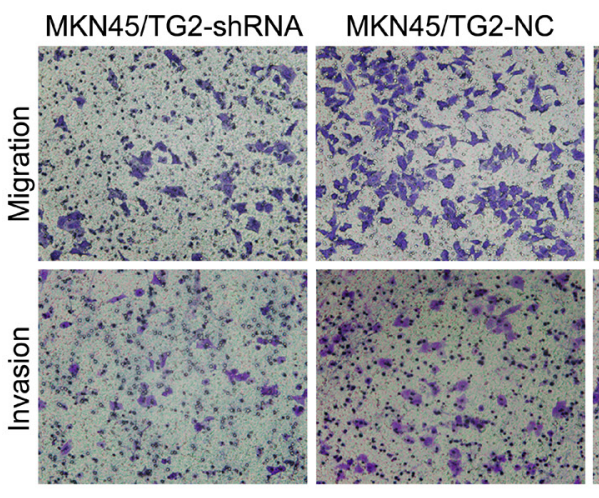

C

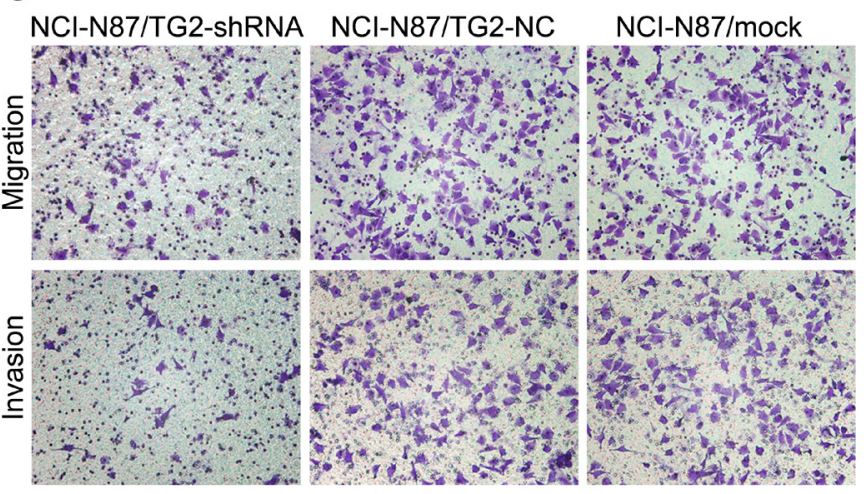

E

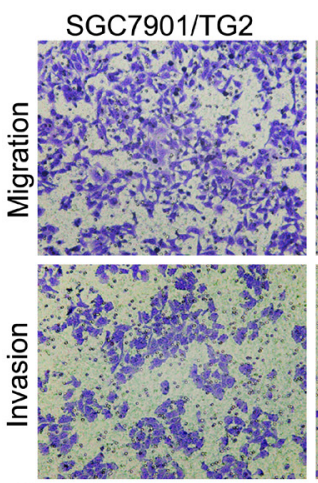

G

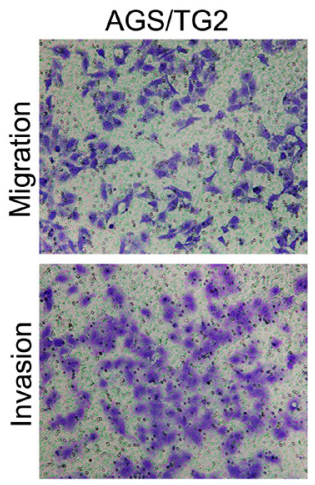

MKN45/mock
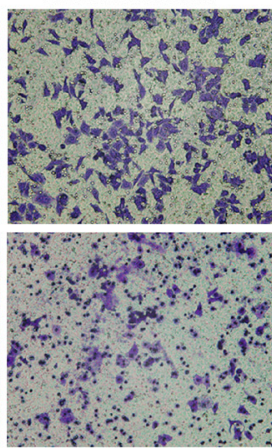

$\mathrm{NCl}$-N87/mock

SGC7901/mock
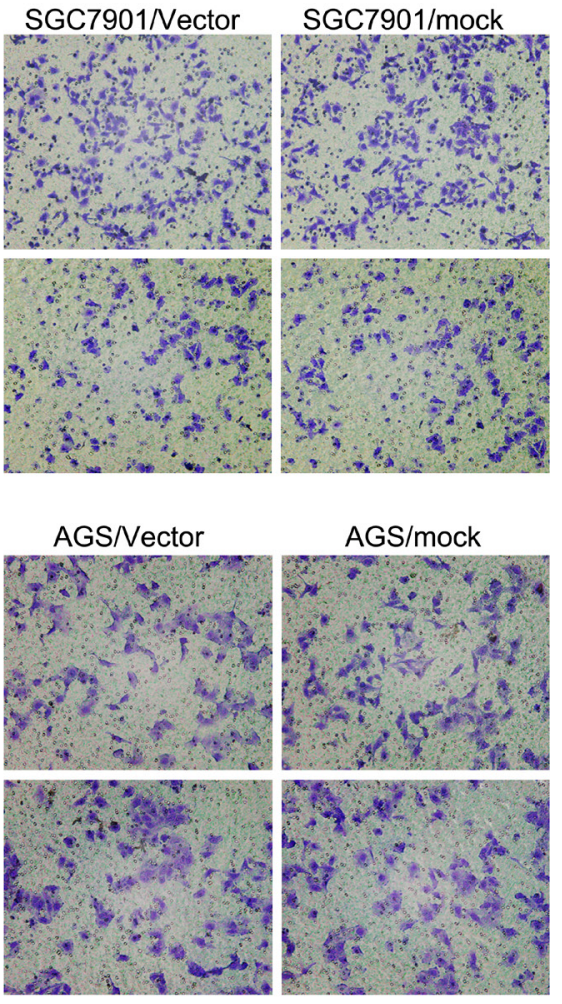

AGS/Vector
B
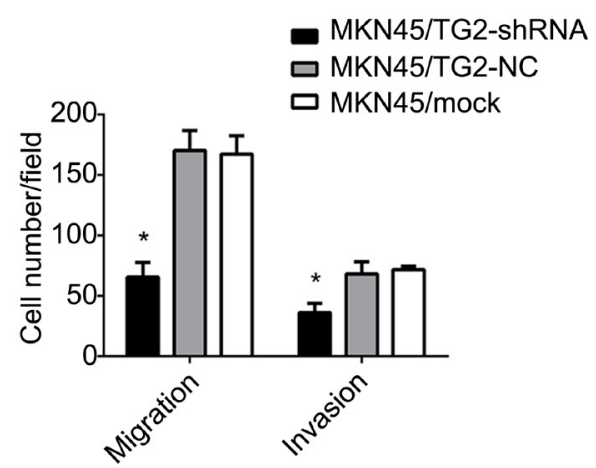

D
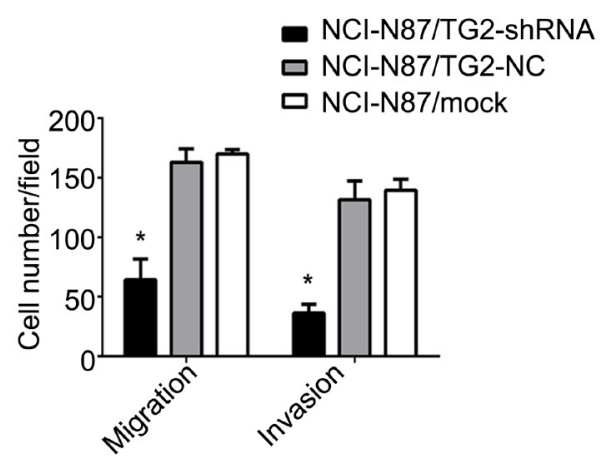

F
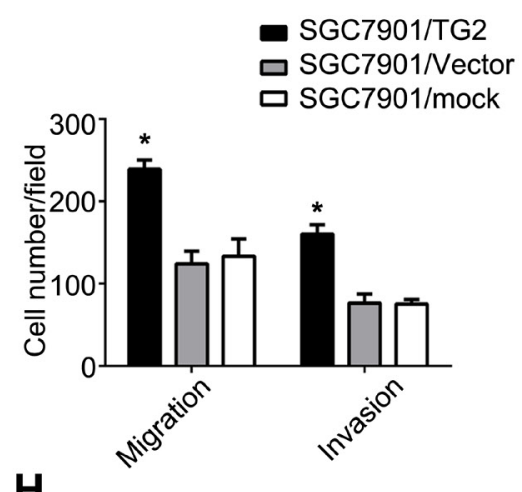

H

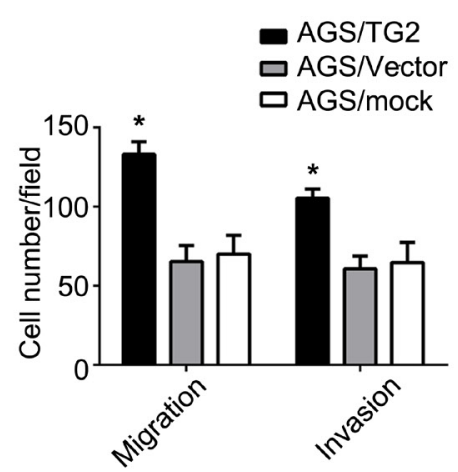

Figure 3: TG2 enhances migration and invasion of GC cells. A., C., E., and G. Effect of knockdown and overexpression of TG2 on cell migration and invasion was assayed and representative photographs of migrating or invaded cells on membranes with or without Matrigel (magnification, 100×) are shown. B., D., F., and H. Histograms depict migrating and invaded cells. Cells were counted in five randomly selected microscopic fields. Data are means $\pm \mathrm{SD}$ of three independent experiments, ${ }^{*} P<0.05$. 
A

C

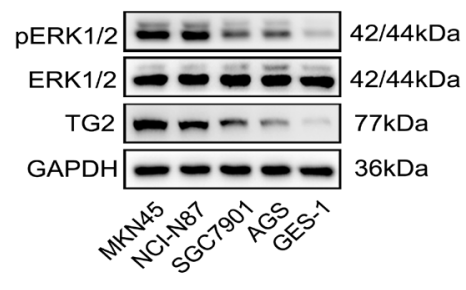
MKN45 NCI-N87

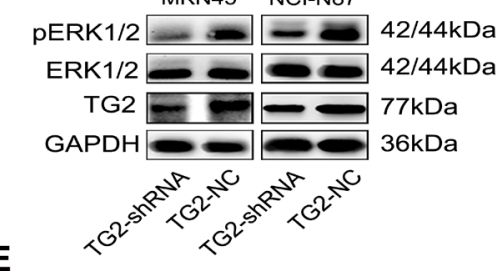
E

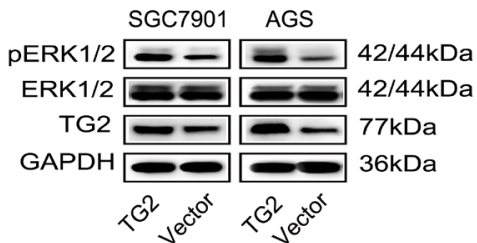

G

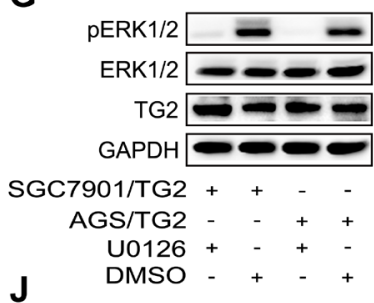

H

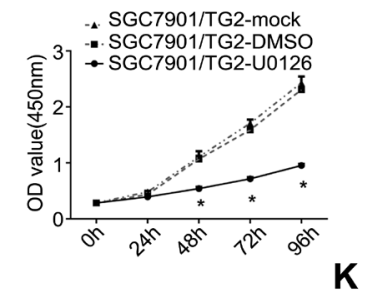

SGC7901/TG2-U0126 SGC7901/TG2-DMSOSGC7901/TG2-mock

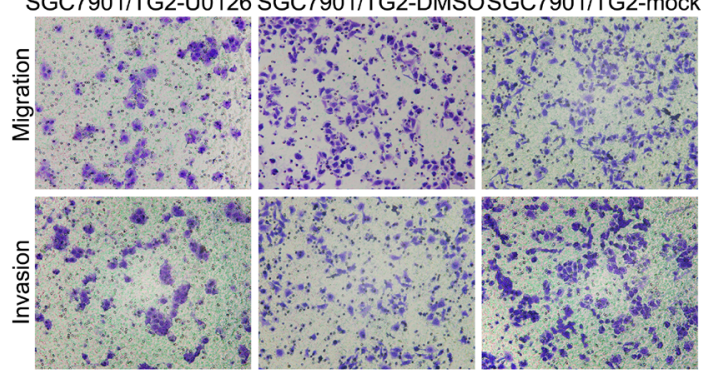

$\mathbf{L}$

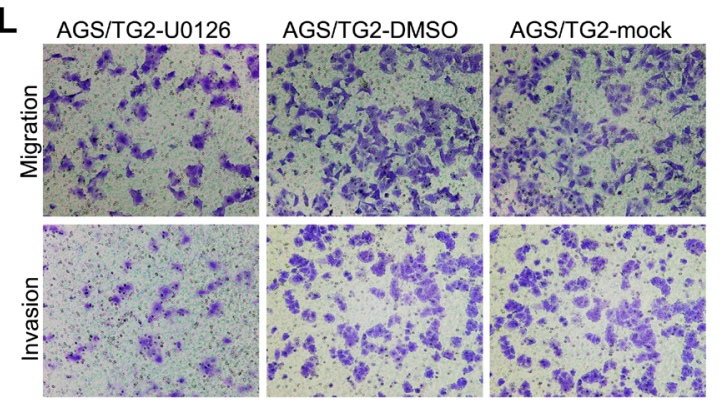

B

D

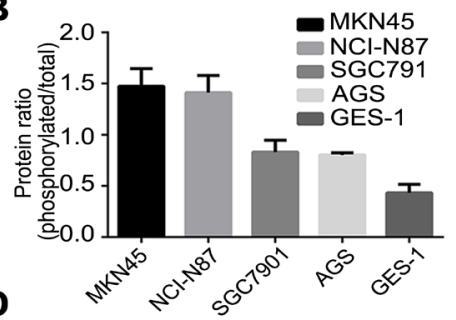

$\mathbf{F}$
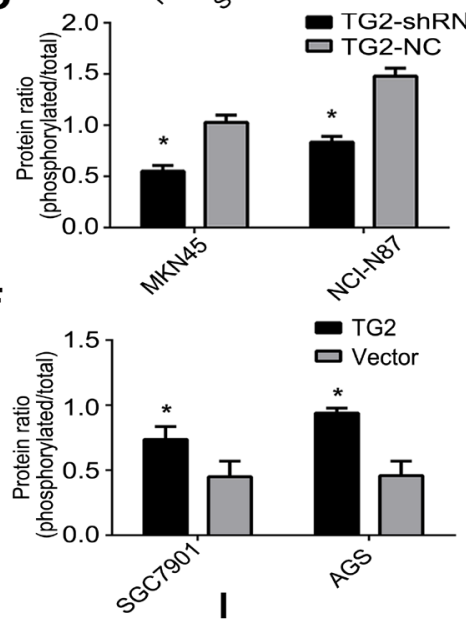

\section{K}

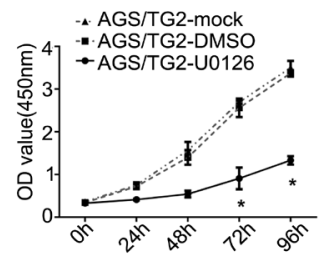

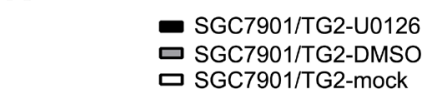

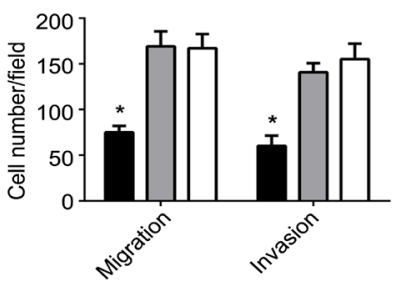

M

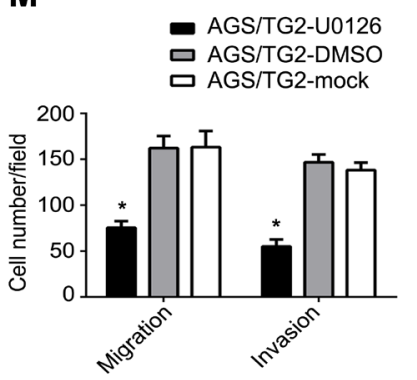

Figure 4: TG2 regulates cell proliferation, migration, and invasion via activation of the ERK1/2 pathway. A. and $B$. ERK1/2 phosphorylation and TG2 expression in GC cells (MKN45, NCI-N87, SGC7901, AGS, and GES-1) were quantified by Western blot. C. and E. Effects of TG2 on ERK1/2 and phosphorylation were measured. D. and F. Protein ratios of pERK1/2 in MKN45, NCI-N87, SGC-7901, and AGS cells. G. After treatment with U0126 at indicated times, ERK1/2 phosphorylation and TG2 expression in SGC7901/ TG2 cells and AGS/TG2 cells were quantified. H. and I. SGC7901/TG2 and AGS/TG2 cell proliferation were assayed in the presence of U0126. J., K., L. and M. Effect of U0126 on cell migration and invasion was assayed and typical photographs (magnification, 100×) and migrating or invaded cells are shown. Data are means \pm SD of three independent experiments, ${ }^{*} P<0.05$. 
A

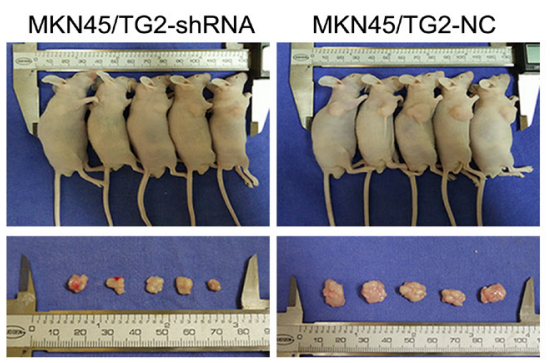

C

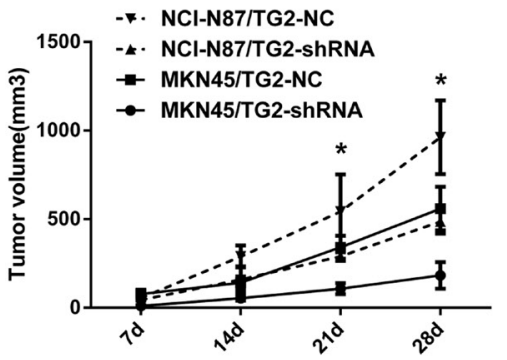

E

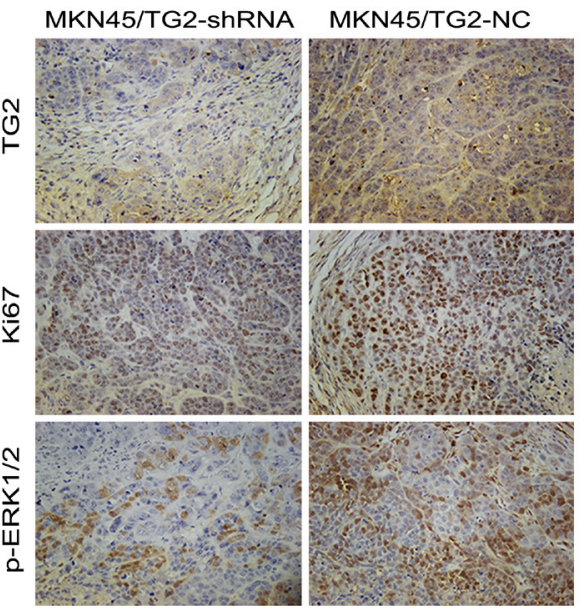

F

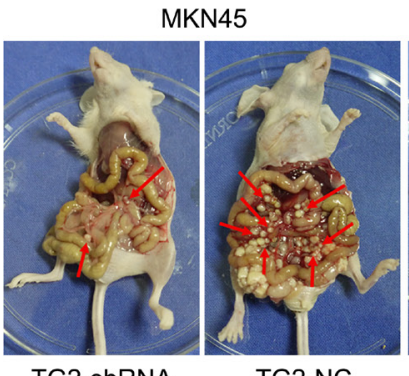

TG2-shRNA
TG2-NC
B

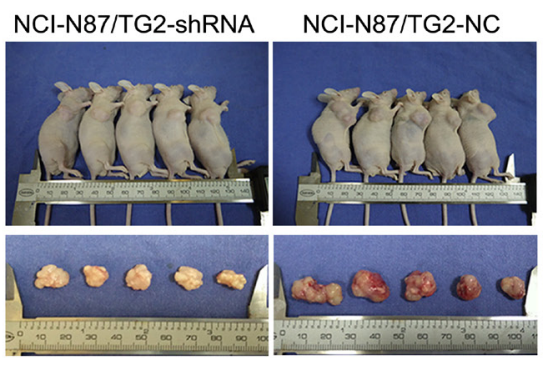

D

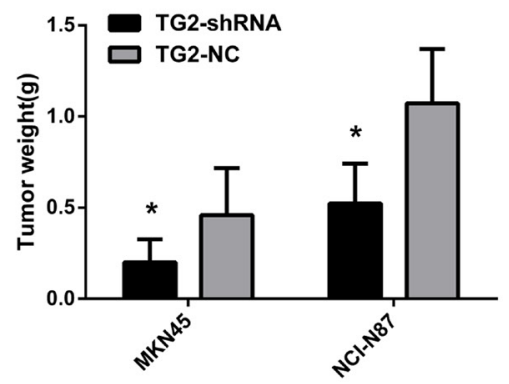

NCI-N87/TG2-shRNA NCI-N87/TG2-NC

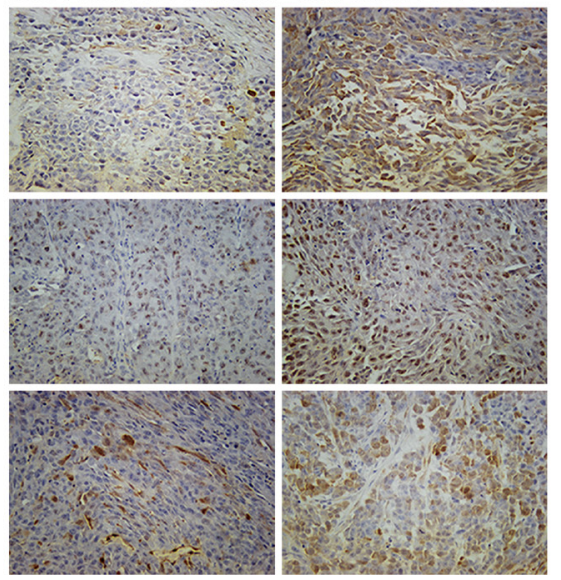

G

Figure 5: Knockdown of TG2 expression inhibits subcutaneous tumor growth and peritoneal and other metastases in nude mice. A. and B. Representative photographs of tumors in nude mice ( $N=5$ per group) derived from MKN45/TG2-shRNA, MKN45/TG2-NC, NCI-N87/TG2-shRNA, and NCI-N87/TG2-NC cells. C. Tumor volume was monitored weekly after treatment with MKN45/TG2-shRNA, MKN45/TG2-NC, NCI-N87/TG2-shRNA, and NCI-N87/TG2-NC cells in nude mice $(* P<0.05)$. D. Average tumor weights derived from MKN45/TG2-shRNA, MKN45/TG2-NC, NCI-N87/TG2-shRNA, or NCI-N87/TG2-NC cells $(\mathrm{N}=5)(* P<$ 0.05). E. Expression of TG2, Ki67, and pERK1/2 was quantified by IHC in tumor grafts from MKN45/TG2-shRNA, MKN45/TG2-NC, NCI-N87/TG2-shRNA, or NCI-N87/TG2-NC cells. Original magnification: 200x. F. MKN45/TG2-shRNA, MKN45/TG2-NC, NCI-N87/ TG2-shRNA, or NCI-N87/TG2-NC cells were inoculated into nude mice, and the peritoneal nodules (red arrows) were observed after 35 days $\left(N=5\right.$ per group). G. Average peritoneal nodules from nude mice are shown $\left({ }^{*} P<0.05\right)$. Data are means $\pm \mathrm{SD}$ of three independent experiments, ${ }^{*} P<0.05$. 
A

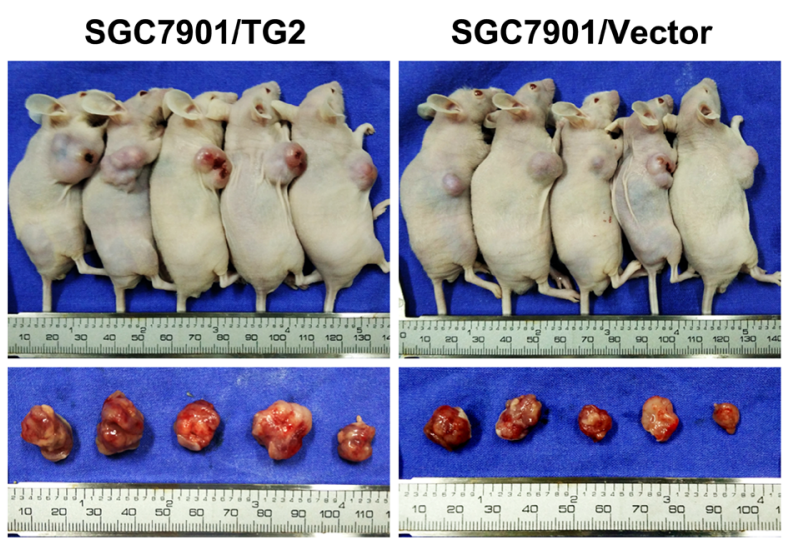

C

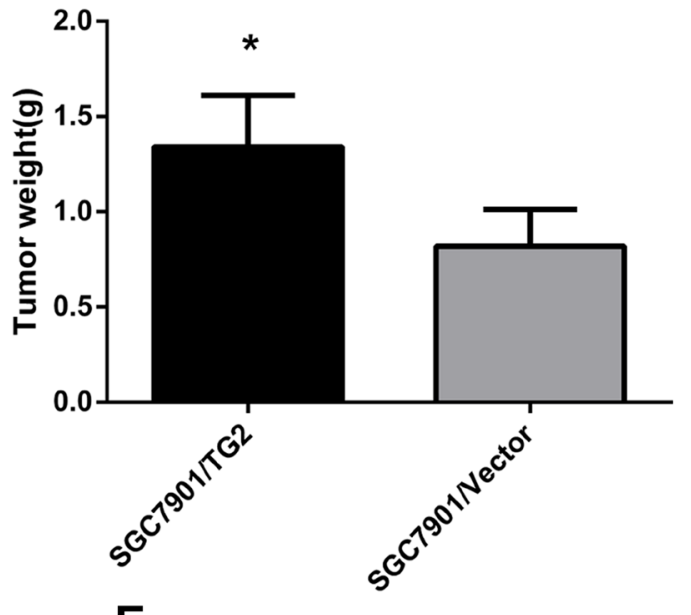

$\mathbf{E}$

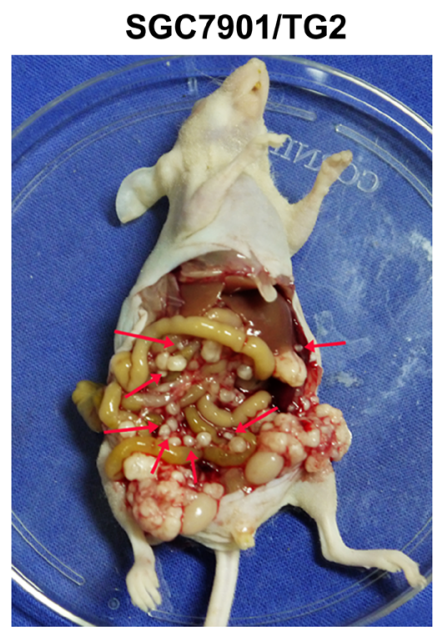

B

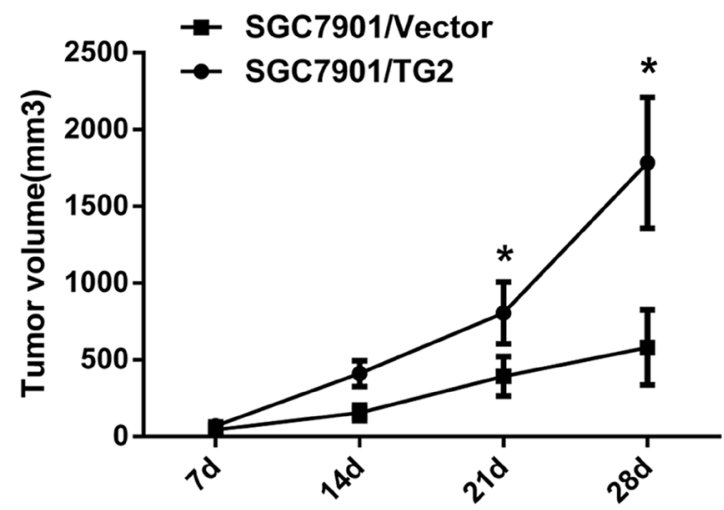

D
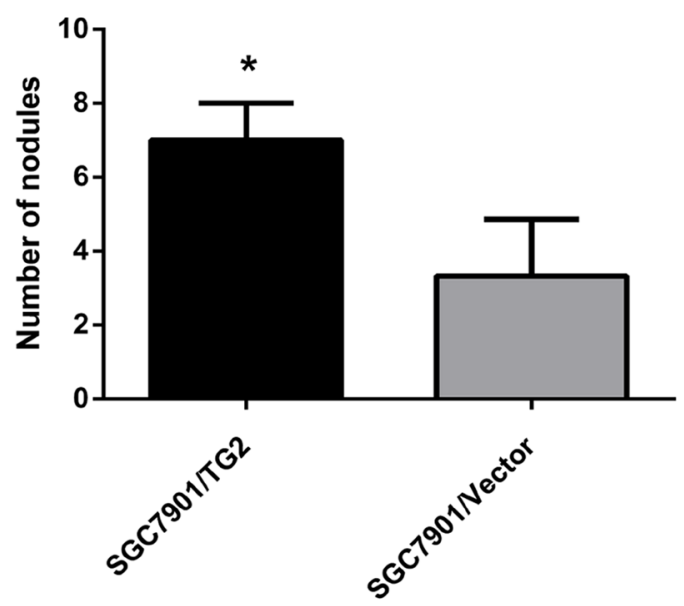

SGC7901/Vector

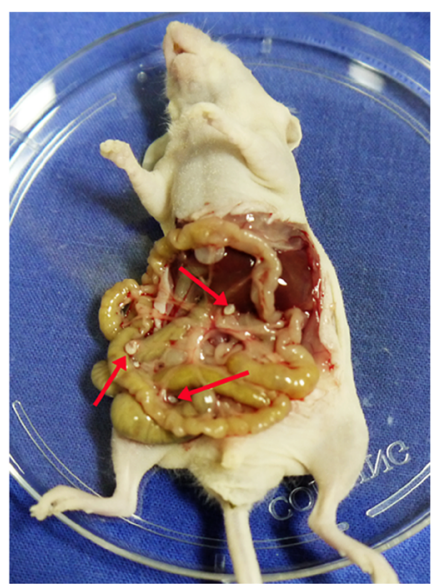

Figure 6: TG2 overexpression promotes subcutaneous tumor growth and peritoneal spread and metastasis in nude mice. A. Representative photographs of nude mice tumors ( $N=5$ per group) derived from SGC7901/TG2 cells and SGC7901/Vector. B. Tumor volume was monitored weekly after treatment with SGC7901/TG2 cells or SGC7901/Vector $(* P<0.05)$. C. Average tumor weight derived from SGC7901/TG2 cells or SGC7901/Vector $(N=5)(* P<0.05)$. D. Average peritoneal nodules from nude mice $(* P<0.05)$. E. SGC7901/TG2 cells or SGC7901/Vector were inoculated into nude mice, and peritoneal nodules (red arrows) were observed after 35 days ( $N=5$ per group). Data are means $\pm \mathrm{SD}$ of three independent experiments, ${ }^{*} P<0.05$. 
compared with tumors derived from controls $(P<0.05)$. To assess whether regulation of the ERK $1 / 2$ pathway by TG2 could be recapitulated in vivo, expression of TG2 and pERK1/2 were measured with IHC, and staining intensity was significantly lower in tumors derived from MKN45/ TG2-shRNA or NCI-N87/TG2-shRNA cells compared with controls. In addition, treatment of nude mice with MKN45/TG2-shRNA or NCI-N87/TG2-shRNA cells inhibited formation of peritoneal metastatic nodules compared with MKN45/TG2-NC and NCI-N87/TG2NC cells (MKN45/TG2-shRNA: 2.00 \pm 0.71 ; MKN45/ TG2-NC: $7.40 \pm 1.14$; MKN45/TG2-shRNA vs. MKN45/ TG2-NC: $P<0.05$; NCI-N87/TG2-shRNA: $2.40 \pm 1.14$; NCI-N87/TG2-NC: 6.20 1.30; NCI-N87/TG2-shRNA vs. NCI-N87/TG2-NC: $P<0.05$ ) (Figure 5F and 5G). Tumors grew more rapidly in the SGC7901/TG2 group and tumor weights (SGC7901/TG2: 1.34 $\pm 0.27 \mathrm{~g}$; SGC7901/Vector: $0.82 \pm 0.19$ g; SGC7901/TG2 vs. SGC7901/Vector: $P<$ $0.05)$ in this group were higher than in the SGC7901/ vector group (Figure 6A, 6B, and 6C). There were significantly more visible peritoneal nodules in the SGC7901/TG2 group compared with controls (SGC7901/TG2: 7.00 \pm 1.00; SGC7901/Vector: 3.33 \pm 1.53 ; SGC7901/TG2 vs. SGC7901/Vector: $P<0.05$ ) (Figure 6D and 6E). We conclude that TG2 promotes tumorigenesis, peritoneal spread, and metastasis of GC in vivo.

\section{DISCUSSION}

Recently, the significance of TG2 non-enzymatic regulation of its own activity has been established [14, $15,24,25]$, and this regulation affects many physiological processes of cell behavior such as cell growth, adhesion, migration, programmed cell death, differentiation, and ECM remodeling [14]. These cellular processes are vital to wound healing, tissue repair, and tumor growth and metastasis [26]. However, aberrant expression of TG2 and its influence on gastric cancer are unclear. Thus, we confirmed that TG2 was a critical regulator of GC progression and that expression of TG2 was frequently upregulated in GC. In addition, TG2 expression was significantly associated with the depth of tumor invasion and late TNM stages.

Multiple studies reveal that increased TG2 expression in diverse cancers and aberrant expression of TG2 are correlated with poor survival, increased drug resistance, and high tumor invasiveness. Specifically, TG2 can enhance pancreatic cancer cell motility and metastatic potential by regulating the TG2/ $\beta 1$ integrin/ Src/uPAR pathway and EMT [27]. In breast cancer, abnormal TG2 expression can lead to glucose metabolism reprogramming, facilitating metabolic alterations of breast cancer cells, promoting drug resistance, and metastatic competence [28]. Down-regulated TG2 expression has been documented in primary tumors and upregulated expression has been confirmed in secondary metastatic tumors [29, 30]. Here, we report that TG2 promoted GC cell proliferation, migration, and invasion in vitro and in vivo with gain- and loss-of-function approaches. Furthermore, TG2 may function as an oncogene in GC and may be associated with GC progression.

TG2 can activate several pathways that contribute to its tumor-promoting properties. Increased TG2 expression is often associated with constitutive activation of NF$\mathrm{kB}$, which protects against ROS-induced cell damage, inflammatory cytokines, and chemotherapeutic drugs [7]. TG2 can also promote degradation of the phosphatase PTEN, constitutively activating the FAK/AKT pathway for regulation of cell survival and chemotherapeutic drug resistance [31]. In addition, cell surface TG2 could interact with integrins, such as $\beta 1, \beta 3$ and $\beta 5$, to promote activation of the FAK/c-Raf/MEK1/2-ERK1/2 pathway [11]. Previous studies indicate that activation of the ERK1/2 pathway is needed for proliferation, migration, and invasion of tumor and non-tumor cells [32-35]. When ERK1/2 pathway activation is inhibited, the effects of umbilical cord-derived mesenchymal stem cells on breast cancer cell proliferation and migration can be reversed [36].

Here, we report that TG2 also regulated cell proliferation, migration, and invasion in GC cells. Specifically, TG2 knockdown suppressed activation of the ERK1/2 pathway, tumor growth, and peritoneal and other metastases in vivo, whereas TG2 overexpression reversed these changes. In addition, inhibition of the ERK1/2 pathway by U0126, a specific ERK1/2 inhibitor, could partially reverse tumor-promoting effects on proliferation, migration, and invasion caused by high TG2 expression, suggesting an involvement of the ERK1/2 pathway in regulating TG2 function in GC cells. The ERK1/2 pathway is documented to mediate tumor metastasis via regulating matrix metalloproteinases (MMPs) expression and activity and this plays a critical role in ECM degradation [37-39], a pivotal step during tumor metastasis [40, 41]. Thus, $\mathrm{TG} 2$, as an upstream regulator of ERK1/2, regulates GC cell proliferation, migration, and invasion by activating the ERK1/2 pathway. Our data provide a foundation for understanding the mechanism of TG2 overexpression in GC progression and suggest that TG2 may be a promising therapeutic target for treating GC.

\section{MATERIALS AND METHODS}

\section{Ethical statement}

Written consent was acquired from all participants who were fully informed of the experimental procedures during the period of research. The study was approved by the Human Research Ethics Committee of Ruijin Hospital, Shanghai Jiaotong University, School of Medicine. All 
experiments on animal were given permission by the Experimental Animal Ethics Committee of Ruijin Hospital and carried out according to the Guide for the Institutional Animal Care and Use Committee (IACUC) of Shanghai Jiaotong University.

\section{Tissue specimens}

GC tissues were obtained from 127 patients, none of who received radiotherapy or chemotherapy before surgery, between 2010 and 2013 at the Ruijin Hospital, Shanghai, China. All the patients included 90 men and 37 women, and the average age was 61.1 years old. The TNM-stage of patients was determined by the UICC TNM classification. All the tissue samples were identified by clinical pathologist and then were fixed by formaldehyde and embedded by paraffin to produce tissue chips.

\section{Cell lines}

Human GC cell lines, MKN45 and NCI-N87, were purchased from Shanghai Institutes for Biological Sciences, Chinese Academy of Sciences. Cells were cultured in the RPMI-1640 medium containing $10 \%$ calf serum with $100 \mathrm{U} / \mathrm{ml}$ penicillin and $100 \mathrm{U} / \mathrm{ml}$ streptomycin and were placed in a humidified cell incubator with $5 \%$ $\mathrm{CO} 2$ at $37^{\circ} \mathrm{C}$.

\section{Quantitative real-time PCR (qRT-PCR)}

Total RNA was isolated with Trizol reagent (Invitrogen, Carlsbad, CA, USA) and cDNA was synthesized with reverse transcription kit (Promega, Madison, WI, USA) following the manufacturer's instructions. QPCR was performed using an Applied Biosystems 7500 System and the SYBR Green Reagent kit (Applied Biosystems, Foster City, CA, USA) to quantitatively analyze the expression levels of TG2. The PCR primers for TG2 were 5'- CGTGACCAACTACAACTCGG-3' (forward) and 5'-CATCCACGACTCCACCCAG-3' (reverse). The PCR primers for GAPDH were 5'-GGACCTGACCTGCCGTCTAG-3' (forward) and 5'GTAGCCCAGGATGCCCTTGA -3' (reverse).

\section{Western blot analysis}

Cells were lysed with RIPA cell lysis buffer in the presence of protease inhibitor cocktail (Sigma, USA). The protein concentration of the cell lysates was quantified by a BCA Protein Assay Kit (Pierce, Rockford, USA). The same amount of protein samples were loaded onto $10 \%$ SDS-PAGE and then transferred onto PVDF membranes. After blocked by skim milk, the membranes were incubated in the primary antibodies diluted by TBST buffer for overnight at $4{ }^{\circ} \mathrm{C}$ and then in the HRP-conjugated secondary antibody for 2-3h at room temperature. Finally the protein bands images were captured by a Tanon detection system with ECL reagent (Thermo). The primary antibodies used in the experiments were anti-TG2 (1:1000; Abcam, USA), anti-ERK1/2 (1:1000; Cell Signaling Technology, USA), anti-pERK1/2 (Thr202/Tyr204) (1:1000; Cell Signaling Technology, USA) and anti-GAPDH (1:10000; Abcam, USA).

\section{Immunohistochemistry (IHC)}

GC tissues sections fixed by formalin and embedded by paraffin were dewaxed in xylene and rehydrated with gradient ethanol. The sections were incubated with rabbit anti-TG2 monoclonal antibody (1:150, Abcam, USA) at $4^{\circ} \mathrm{C}$ overnight, prior to which antigen retrieval was performed by boiling in $0.01 \mathrm{~mol} / \mathrm{L}$ citrate buffer ( $\mathrm{pH}$ 6.0). The immune complex was detected by a standard avidinbiotin detection system with the LSAB+ kit (Dako, USA). The nuclei were counterstained with hematoxylin. The sections were evaluated by three pathologists who were blinded to clinicopathologic information. TG2 staining score $=$ positive cell score + staining intensity score. The percentage of positive cells was classified by four grades (percentage scores): $0(0),<1 / 3$ (1), 1/3-2/3 (2) and $>2 / 3$ (3). The intensity of staining was also divided into four grades (intensity scores): no staining (0), weak staining (1), moderate staining (2) and strong staining (3). The overall scores $0,1-2,3-4$, and 5-6 were defined as negative $(-)$, weak positive $( \pm)$, moderate positive $(+)$, and strong positive $(++)$ respectively.

\section{Plasmids construction and transfection}

The TG2 shRNA was purchased from Shanghai GeneChem Co, Ltd. The target sequence was 5'AAATACCGTGACTGCCTTA- ${ }^{\prime}$ and the negative control sequence was 5'-TTCTCCGAACGTGTCACGT-3'. The shRNA plasmid construction was hU6-MCS-UbiquitinEGFP-IRES-puromycin. The TG2 shRNA and negative control plasmids were transfected into MKN45 cells and NCI-N87 cells using Lipofectamine2000 (Invitrogen, Carlsbad, CA, USA), respectively. Then the stable transfected cell lines (MKN45/TG2-shRNA, MKN45/ TG2-NC, NCI-N87/TG2-shRNA, NCI-N87/TG2-NC) were screened by using puromycin and western blot was performed for identification.

The full length TG2 cDNA was obtained by RT-PCR from total RNA of GC samples. The primer sequences of TG2 were 5' ACGGGCCCTCTAGACTCGAGCGCCACCATGG CCGAGGAGCTGGTCTTAGAG - 3' (forward), 5' - AGTCCAGTGTGGTGGAATTCGGCGGGG 
CCAATGATGACATTCC-3' (reverse) and subcloned into CMV-MCS-3FLAG-SV40-Neomycin plasmid (GeneChem, Shanghai, China). The constructed plasmid and empty vector were transfected into SGC-7901 and AGS cells using Lipofectamine 2000 (Invitrogen, Carlsbad, CA, USA) in accordance with the manufacturer's protocol. Stable clones (SGC7901/TG2, SGC7901/Vector, AGS/TG2, AGS/Vector) were selected by using G418 (1.2 mg/ml; Gibco, New York, USA).

\section{Cell proliferation assay}

Cells $\left(2 \times 10^{3} /\right.$ well) were seeded into 96 -well plates for 4 days, and cell proliferation was measured by spectrophotometer at 0h, 24h, 48h, 72h and 96h using a Cell Counting Kit-8 (Dojindo, Kumamoto, Japan) according to the manufacturer's instructions.

\section{Cell migration and invasion assay}

Cell migration and invasion assays were assessed using transwell chambers (Corning Costar, NY, USA). Cells were cultured in serum-free RPMI-1640 for 12-16h, and then $1 \times 10^{5}$ cells in 200 ul serum-free medium were seeded into the upper chamber, and 800ul medium with $10 \%$ fetal calf serum was added to the lower chamber. For the invasion assay, the insert membranes were coated with diluted matrigel (BD Bioscience, CA, USA). After cultured for $24 \mathrm{~h}$, cells that did not move through the membranes were removed and then the membranes were stained with $0.1 \%$ crystal violet for $30 \mathrm{~min}$. The stained cells were counted and photographed using an inverted microscope.

\section{In vivo tumorigenesis and metastasis}

Four-week-old male BALB/C nude mice, which were purchased from the Institute of Zoology, Chinese Academy of Sciences and housed at a specific pathogenfree environment, were injected subcutaneously with $6 \times 10^{5}$ gastric cancer cells in $100 \mu \mathrm{l}$ PBS or inoculated peritoneally with $2 \times 10^{6}$ cells in $250 \mu \mathrm{l}$ PBS. Tumor length (L) and width (W) were measured every week. Tumor volume was evaluated using the following formula: tumor volume $=\mathrm{LW}^{2} \pi / 6$. All mice were sacrificed after 30 days. Subcutaneous tumor grafts were excised and weighed, and peritoneal metastasis nodules were counted and analyzed.

\section{Statistical analysis}

The experimental results were analyzed by SPSS 18.0 software and shown as mean \pm standard deviation (SD). The relationship between the expression level of TG2 and clinicopathologic parameters was examined by the Pearson $\chi 2$ test or Fisher's exact tests. The differences between the two groups were calculated by the Student's t test. The significance level was set at $P<0.05$.

\section{ACKNOWLEDGMENTS}

We thank LetPub (www.letpub.com) for its linguistic assistance during the preparation of this manuscript.

\section{GRANT SUPPORT}

This study was supported by grants from National Natural Science Foundation of China (No.81272749, No.81572798, No.91229106, and No.91529302), Shanghai Municipal Education Commission-Gaofeng Clinical Medicine Grant Support (20152505), Doctoral Innovation Fund Projects from Shanghai Jiao Tong University School of Medicine (BXJ201318).

\section{CONFLICTS OF INTEREST}

The authors made no disclosures.

\section{REFERENCES}

1. Ferlay J, Soerjomataram I, Ervik M, Dikshit R, Eser S, Mathers C, Rebelo M, Parkin D, Forman D and Bray F. GLOBOCAN 2012 v1.0, Cancer Incidence and Mortality Worldwide: IARC CancerBase No. 11 [Internet]. Lyon, France: International Agency for Research on Cancer; 2013. Available from: http://globocan.iarc.fr, accessed on day/ month/year.

2. Hundahl SA, Phillips JL and Menck HR. The National Cancer Data Base Report on poor survival of U.S. gastric carcinoma patients treated with gastrectomy: Fifth Edition American Joint Committee on Cancer staging, proximal disease, and the "different disease" hypothesis. Cancer. 2000; 88:921-932.

3. Lorand L and Conrad SM. Transglutaminases. Molecular and cellular biochemistry. 1984; 58:9-35.

4. Facchiano A and Facchiano F. Transglutaminases and their substrates in biology and human diseases: 50 years of growing. Amino acids. 2009; 36:599-614.

5. Mehta K, Kumar A and Kim HI. Transglutaminase 2: a multi-tasking protein in the complex circuitry of inflammation and cancer. Biochemical pharmacology. 2010; 80:1921-1929.

6. Chen JS and Mehta K. Tissue transglutaminase: an enzyme with a split personality. The international journal of biochemistry \& cell biology. 1999; 31:817-836.

7. Brown KD. Transglutaminase 2 and NF-kappaB: an odd couple that shapes breast cancer phenotype. Breast cancer research and treatment. 2013; 137:329-336.

8. Nakaoka H, Perez DM, Baek KJ, Das T, Husain A, Misono 
K, Im MJ and Graham RM. Gh: a GTP-binding protein with transglutaminase activity and receptor signaling function. Science. 1994; 264:1593-1596.

9. Hasegawa G, Suwa M, Ichikawa Y, Ohtsuka T, Kumagai S, Kikuchi M, Sato Y and Saito Y. A novel function of tissue-type transglutaminase: protein disulphide isomerase. The Biochemical journal. 2003; 373:793-803.

10. Mishra S and Murphy LJ. Tissue transglutaminase has intrinsic kinase activity: identification of transglutaminase 2 as an insulin-like growth factor-binding protein-3 kinase. The Journal of biological chemistry. 2004; 279:2386323868.

11. Belkin AM. Extracellular TG2: emerging functions and regulation. The FEBS journal. 2011; 278:4704-4716.

12. Kim SY. Transglutaminase 2 in inflammation. Frontiers in bioscience. 2006; 11:3026-3035.

13. Sarang Z, Toth B, Balajthy Z, Koroskenyi K, Garabuczi E, Fesus L and Szondy Z. Some lessons from the tissue transglutaminase knockout mouse. Amino acids. 2009; 36:625-631.

14. Zemskov EA, Janiak A, Hang J, Waghray A and Belkin AM. The role of tissue transglutaminase in cell-matrix interactions. Frontiers in bioscience. 2006; 11:1057-1076.

15. Janiak A, Zemskov EA and Belkin AM. Cell surface transglutaminase promotes RhoA activation via integrin clustering and suppression of the Src-p190RhoGAP signaling pathway. Molecular biology of the cell. 2006; 17:1606-1619.

16. Schmitt JM, Abell E, Wagner A and Davare MA. ERK activation and cell growth require CaM kinases in MCF7 breast cancer cells. Molecular and cellular biochemistry. 2010; 335:155-171.

17. Assi J, Srivastava G, Matta A, Chang MC, Walfish PG and Ralhan R. Transglutaminase 2 overexpression in tumor stroma identifies invasive ductal carcinomas of breast at high risk of recurrence. PloS one. 2013; 8:e74437.

18. Verma A, Guha S, Diagaradjane P, Kunnumakkara AB, Sanguino AM, Lopez-Berestein G, Sood AK, Aggarwal BB, Krishnan S, Gelovani JG and Mehta K. Therapeutic significance of elevated tissue transglutaminase expression in pancreatic cancer. Clinical cancer research. 2008; 14:2476-2483.

19. Kotsakis P, Wang Z, Collighan RJ and Griffin M. The role of tissue transglutaminase (TG2) in regulating the tumour progression of the mouse colon carcinoma CT26. Amino acids. 2011; 41:909-921.

20. Jeong JH, Cho BC, Shim HS, Kim HR, Lim SM, Kim SK, Chung KY, Ul Islam SM, Song JJ, Kim SY and Kim JH. Transglutaminase 2 expression predicts progression free survival in non-small cell lung cancer patients treated with epidermal growth factor receptor tyrosine kinase inhibitor. Journal of Korean medical science. 2013; 28:1005-1014.

21. Khanna M, Chelladurai B, Gavini A, Li L, Shao M, Courtney D, Turchi JJ, Matei D and Meroueh S.
Targeting ovarian tumor cell adhesion mediated by tissue transglutaminase. Molecular cancer therapeutics. 2011; 10:626-636.

22. Cao L, Shao M, Schilder J, Guise T, Mohammad KS and Matei D. Tissue transglutaminase links TGF-beta, epithelial to mesenchymal transition and a stem cell phenotype in ovarian cancer. Oncogene. 2012; 31:2521-2534.

23. Xie KM, Hou XF, Li MQ and Li DJ. NME1 at the human maternal-fetal interface downregulates titin expression and invasiveness of trophoblast cells via MAPK pathway in early pregnancy. Reproduction. 2010; 139:799-808.

24. Akimov SS, Krylov D, Fleischman LF and Belkin AM. Tissue transglutaminase is an integrin-binding adhesion coreceptor for fibronectin. The Journal of cell biology. 2000; 148:825-838.

25. Scarpellini A, Germack R, Lortat-Jacob H, Muramatsu T, Billett E, Johnson T and Verderio EA. Heparan sulfate proteoglycans are receptors for the cell-surface trafficking and biological activity of transglutaminase-2. The Journal of biological chemistry. 2009; 284:18411-18423.

26. Hand D, Dias D and Haynes LW. Stabilization of collagentailed acetylcholinesterase in muscle cells through extracellular anchorage by transglutaminase-catalyzed cross-linking. Molecular and cellular biochemistry. 2000; 204:65-76.

27. Ashour AA, Gurbuz N, Alpay SN, Abdel-Aziz AA, Mansour AM, Huo L and Ozpolat B. Elongation factor-2 kinase regulates $\mathrm{TG} /$ /betal integrin/Src/uPAR pathway and epithelial-mesenchymal transition mediating pancreatic cancer cells invasion. Journal of cellular and molecular medicine. 2014; 18:2235-2251.

28. Kumar S, Donti TR, Agnihotri N and Mehta K. Transglutaminase 2 reprogramming of glucose metabolism in mammary epithelial cells via activation of inflammatory signaling pathways. International journal of cancer. 2014; 134:2798-2807.

29. Verma A and Mehta K. Tissue transglutaminase-mediated chemoresistance in cancer cells. Drug resistance updates. 2007; 10:144-151.

30. Mangala LS, Fok JY, Zorrilla-Calancha IR, Verma A and Mehta K. Tissue transglutaminase expression promotes cell attachment, invasion and survival in breast cancer cells. Oncogene. 2007; 26:2459-2470.

31. Wang Y, Ande SR and Mishra S. Phosphorylation of transglutaminase 2 (TG2) at serine-216 has a role in TG2 mediated activation of nuclear factor-kappa $\mathrm{B}$ and in the downregulation of PTEN. BMC cancer. 2012; 12:277.

32. Sharma GD, He J and Bazan HE. p38 and ERK1/2 coordinate cellular migration and proliferation in epithelial wound healing: evidence of cross-talk activation between MAP kinase cascades. The Journal of biological chemistry. 2003; 278:21989-21997.

33. Mu H, Wang X, Wang H, Lin P, Yao Q and Chen C. Lactosylceramide promotes cell migration and proliferation 
through activation of ERK1/2 in human aortic smooth muscle cells. American journal of physiology Heart and circulatory physiology. 2009; 297:H400-408.

34. Steinmetz R, Wagoner HA, Zeng P, Hammond JR, Hannon TS, Meyers JL and Pescovitz OH. Mechanisms regulating the constitutive activation of the extracellular signalregulated kinase (ERK) signaling pathway in ovarian cancer and the effect of ribonucleic acid interference for ERK1/2 on cancer cell proliferation. Molecular endocrinology. 2004; 18:2570-2582.

35. Sun Y, Zhu D, Wang G, Wang D, Zhou H, Liu X, Jiang M, Liao L, Zhou Z and Hu J. Pro-Inflammatory Cytokine IL-1beta Up-Regulates CXC Chemokine Receptor 4 via Notch and ERK Signaling Pathways in Tongue Squamous Cell Carcinoma. PloS one. 2015; 10:e0132677.

36. Li T, Zhang C, Ding Y, Zhai W, Liu K, Bu F, Tu T, Sun L, Zhu W, Zhou F, Qi W, Hu J, Chen H and Sun X. Umbilical cord-derived mesenchymal stem cells promote proliferation and migration in MCF-7 and MDA-MB-231 breast cancer cells through activation of the ERK pathway. Oncology reports. 2015; 34:1469-1477.

37. Inamoto T, Azuma H, Sakamoto T, Kiyama S, Ubai T, Kotake Y, Watanabe M and Katsuoka Y. Invasive ability of human renal cell carcinoma cell line Caki-2 is accelerated by gamma-aminobutyric acid, via sustained activation of ERK1/2 inducible matrix metalloproteinases. Cancer investigation. 2007; 25:574-583.

38. Byun HJ, Hong IK, Kim E, Jin YJ, Jeoung DI, Hahn JH, Kim YM, Park SH and Lee H. A splice variant of CD99 increases motility and MMP-9 expression of human breast cancer cells through the AKT-, ERK-, and JNK-dependent AP-1 activation signaling pathways. The Journal of biological chemistry. 2006; 281:34833-34847.

39. Luo Y, Liang F and Zhang ZY. PRL1 promotes cell migration and invasion by increasing MMP2 and MMP9 expression through Src and ERK1/2 pathways. Biochemistry. 2009; 48:1838-1846.

40. Rucci N, Sanita P and Angelucci A. Roles of metalloproteases in metastatic niche. Current molecular medicine. 2011; 11:609-622.

41. Deryugina EI and Quigley JP. Matrix metalloproteinases and tumor metastasis. Cancer metastasis reviews. 2006; 25:9-34. 